\title{
Development of ITS sequence-based markers to distinguish Berberis aristata DC. from B. lycium Royle and B. asiatica Roxb.
}

\author{
Subramani Paranthaman Balasubramani • \\ Gurinder Singh Goraya · Padma Venkatasubramanian
}

Received: 12 October 2010/ Accepted: 3 December 2010/Published online: 18 January 2011

(C) The Author(s) 2011. This article is published with open access at Springerlink.com

\begin{abstract}
The stems of Berberis aristata DC. (Berberidaceae) are used in the South Asian traditional medicine as a key ingredient in formulations for eye care, skin diseases, jaundice, rheumatism and also in diabetes. B. lycium Royle and B. asiatica Roxb. are traded as equivalents of $B$. aristata. Conventional macro-morphology and microscopic examination does not aid in critically distinguishing the three species. DNA markers were developed by amplifying and sequencing the complete internal transcribed spacer region (ITS1, 5.8S rRNA and ITS2) from the genomic DNA, using universal primers. The markers developed are efficient and reliable in authenticating B. aristata, B. asiatica and B. lycium. These are useful as molecular pharmacognostic tool in quality control of raw drugs.
\end{abstract}

Keywords Daruharidra - Berberis spp. - Quality control · Internal transcribed spacer (ITS) · DNA marker

\section{Introduction}

Medicinal herbs are moving from fringe to mainstream use with a greater number of people seeking remedies and health approaches free from side effects caused by

\footnotetext{
S. P. Balasubramani · P. Venkatasubramanian ( $\square)$

Centre for Pharmacognosy, Pharmaceutics and Pharmacology, Institute of Ayurveda and Integrative Medicine (I-AIM), Foundation for Revitalization of Local Health Traditions (FRLHT), 74/2, Jarakabande Kaval, Attur Post, Via Yelahanka, Bangalore 560106, India e-mail: padma.venkat@frlht.org

G. S. Goraya

Indian Forest Service, Sundernagar,

Mandi 174402, Himachal Pradesh, India
}

synthetic chemicals (Dubey et al. 2004). With so much demand for traditional herbal medicines, it is imperative to ensure and maintain authenticity of the various botanical entities used as raw material. However, the conventional quality assurance tools sometimes have limitations in critical identification of raw materials derived from closely related species, substitutes or adulterants.

'Daruharidra' (in Sanskrit means 'the wood having yellow color') is one such botanical entity that poses problems in terms of field identification. Botanically correlated to Berberis aristata DC. (Berberidaceae) it has been used in Ayurveda and Traditional Chinese Medicine for the past 3,000 years (Anonymous 1999; Sack and Froehlich 1982). In Ayurveda, it forms a key ingredient in preparation of formulations for eye care, wounds, skin diseases, jaundice, rheumatism and also in diabetes (Anonymous 1999). The genus Berberis constitutes of spinous shrubs distributed throughout the Himalayas, from Bhutan to Kunawar (altitude 6,000-10,000 ft) in India and Sri Lanka (altitude 6,000-7,000 ft) (Kirtikar and Basu 1995). B. aristata is a plant species of high trade sourced from temperate forests. The present annual production and supply of B. aristata in India is dependent only from the state of Himachal Pradesh (Ved and Goraya 2008).

In field, more than one species of Berberis usually occur together. The nature of the Berberis species varies with place and the leaves exhibit great variations (Rao et al. 1998). So, Rao et al. (1999) reported pollen morphologic studies in solving taxonomic problem in this complex group. Since harvesting of Berberis spp. takes place during winter months when the key phenological features for identification are not present, it becomes difficult to distinguish one species from the other in the field. Thus, species other than $B$. aristata are also harvested. Since stems are the parts used it becomes even more challenging 
to obtain authentic collections and assure quality. As a result, $B$. asiatica Roxb. and B. lycium Royle are traded and used as equivalents/substitutes of $B$. aristata (Anonymous 2003; Ved and Goraya 2008). Conventional Pharmacognosy techniques based on macro-morphological characters may not be effective in distinguishing the three species traded as 'Daruharidra'. Further, related species may share similar histological characteristics, making microscopic examination not so accurate (Yan-Bo et al. 2007).

Different species of the same genus may have totally different or weaker pharmacological action as compared with the authentic counterpart (Yip et al. 2007). Therefore, more objective and definitive methods are necessary for identification and authentication of herbs. Extracts of B. aristata are said to possess anti-amebic (Sohni et al. 1995), anti-microbial (Singh et al. 2007), wound healing (Biswas and Mukherjee 2003), anti-oxidant and anti-hyperglycemic properties (Singh and Kakkar 2009). B. asiatica has been reported to have anti-microbial and anti-tumor effects (Kumar et al. 1998; Singh et al. 2007) while B. lycium is reported to possess anti-bacterial, anti-diabetic effect and is also used to treat bleeding piles (Singh et al. 2007; Ahmad and Alamgeer 2009).

Berberine, an alkaloid is considered to be the active compound present in Berberis spp. with diverse pharmacological effects and is also considered as a nutraceutical (Saied et al. 2007; Wongbutdee 2009; Affuso et al. 2009). Since, berberine is present in all the three species of Berberis, i.e., B. aristata, B. lycium and B. asiatica, with inherent inter and intra species quantitative differences, phytochemical profiling may not reflect the exact identity of the raw drug (Chandraa and Purohita 1980; Srivastava et al. 2004). The annual trade of Daruharidra including the substitutes is estimated to be 500-1,000 Metric Tonnes
(Ved and Goraya 2008). According to the WHO general guidelines for methodologies on research and evaluation of traditional medicines, first step in assuring quality, safety and efficacy of traditional medicines is correct identification (World Health Organization 2000).

DNA-based markers have now become a popular means for the identification and authentification of plants because genetic composition is unique for each individual irrespective of the physical form and is less affected by age, physiological condition, environmental factors, harvest, storage and processing. DNA extracted from leaves, stems or roots of a herb all carry the same genetic information and extracted DNA can be stored for longer duration as they are stable (Yip et al. 2007). Nuclear ribosomal RNA genes and internal transcribed spacer (ITS) sequences have become favored markers in evolutionary studies at different taxonomic levels. In recent days, these sequence variations are used to develop specific markers for the identification and authentication of raw drugs and herbal formulations (Yan-Bo et al. 2007; Balasubramani et al. 2010).

The objective of the present investigation was to develop molecular markers for distinguishing B. aristata, B. asiatica and B. lycium based on their nuclear DNA ITS sequence.

\section{Materials and methods}

\section{Plant material}

Field samples of B. aristata, B. asiatica and B. lycium, were collected from different geographical locations of Himachal Pradesh in India. The authenticity of the samples was confirmed by qualified taxonomist. Each sample was assigned a specific laboratory identification number as
Table 1 Details of the Berberis sp. stem samples used in the study
The accessions were collected from different locations of Himachal Pradesh, India (HP-latitude $32^{\circ} 29^{\prime} \mathrm{N}$; longitude $\left.75^{\circ} 10^{\prime} \mathrm{E}\right)$

\begin{tabular}{llll}
\hline Si no. & Name of the species & Place of collection & Accession No. \\
\hline 1 & B. aristata & Taradevi forest, Shimla & $\mathrm{L} / 06 / 10 / 010$ \\
2 & & Taradevi forest, Shimla & $\mathrm{L} / 06 / 10 / 011$ \\
3 & Potter's hill, Shimla & $\mathrm{L} / 08 / 09 / 012$ \\
4 & Shillaru, Shimla & $\mathrm{L} / 08 / 10 / 008$ \\
5 & Potter's Hills, Shimla & $\mathrm{L} / 08 / 10 / 011$ \\
& & \\
6 & & Mulshi, Mussoorie & $\mathrm{L} / 07 / 12 / 001$ \\
7 & B. asiatica & Urla village, Mandi Dt. & $\mathrm{L} / 08 / 03 / 001$ \\
8 & & Saharan-Nahan Road & $\mathrm{L} / 08 / 09 / 013$ \\
9 & Saharan-Nahan road & $\mathrm{L} / 08 / 09 / 016$ \\
10 & & \\
11 & K. lycium & Karol, Manikaran, Kullu Dt. & $\mathrm{L} / 06 / 06 / 037$ \\
12 & & $\mathrm{~L} / 06 / 10 / 008$ \\
13 & & Kangra, Palmpur & $\mathrm{L} / 08 / 09 / 014$ \\
14 & & Shillaru, Kangra & $\mathrm{L} / 08 / 10 / 009$ \\
\hline
\end{tabular}


indicated in Table 1. Voucher specimens were deposited in the Herbarium and Raw Drug Repository (FRLH), Bangalore, India.

\section{Chemicals}

Tris-HCl, EDTA, NaCl, Cethyltrimethylammonium bromide (CTAB), Polyvinyl pyrrolidone (PVP), $\beta$ mercaptoethanol, isopropanol, agarose, boric acid, and ethanol were purchased from Sigma Chemicals (Sigma-Aldrich, Bangalore, India). Enzymes (Taq Polymerase and RNase A), buffer, $\mathrm{MgCl}_{2}$ and dNTPs for PCR amplification were purchased from Bangalore Genei (Bangalore, India).

\section{Genomic DNA extraction}

Stem samples of B. aristata, B. asiatica and B. lycium were cut into small pieces and dried in a dehydrator at $48-50{ }^{\circ} \mathrm{C}$ (Hardfacts, Mumbai, India) until a constant dry weight is obtained. The dried stem pieces were stored at room temperature until use. Total genomic DNA was extracted following the protocol described by Milligan (1998) with modifications. The dried stem pieces were ground into coarse powder in a domestic blender. Approximately, $100 \mathrm{mg}$ of the coarse powder was ground with liquid nitrogen to a fine powder. Extraction buffer containing $2 \%$ (w/v) CTAB, $1.4 \mathrm{M} \mathrm{NaCl}, 20 \mathrm{mM}$ EDTA, $100 \mathrm{mM}$ Tris$\mathrm{HCl}(\mathrm{pH} 8), 1 \%(\mathrm{w} / \mathrm{v}) \mathrm{PVP}$ and $0.2 \%$ (v/v) $\beta$ mercaptoethanol ( $\mathrm{pH} 7.5-8.0)$ was added to the powder. The slurry was incubated at $60{ }^{\circ} \mathrm{C}$ in a water bath for $60-90 \mathrm{~min}$ followed by extraction using chloroform:isoamyl alcohol $(24: 1)(\mathrm{v} / \mathrm{v})$ with centrifugation at $9,000 \mathrm{rpm}$ for $10 \mathrm{~min}$ at $4{ }^{\circ} \mathrm{C}$. The aqueous phase was collected and the extraction process was repeated twice. Finally, the DNA was precipitated from pooled aqueous phase using ice cold ethanol. Nucleic acid was recovered by centrifugation at 8,000 rpm for $15 \mathrm{~min}$ at $4{ }^{\circ} \mathrm{C}$ and the pellet was dissolved in $\mathrm{TE}$ buffer (10 mM Tris-Hcl, $1 \mathrm{mM}$ EDTA; pH 8). The contaminating RNA was removed by treating with RNase A $(20 \mu \mathrm{g} / \mu \mathrm{L})$ for $30 \mathrm{~min}$ at $37^{\circ} \mathrm{C}$. The quantity and purity of DNA were checked using UV spectrophotometer by calculating the $A_{260} / A_{280}$ ratio (Shimadzu, Tokyo, Japan) (Fai and Ngan 2002). The DNA stock concentration was maintained at $30-50 \mathrm{ng} / \mu \mathrm{L}$.

\section{Amplification of ITS region}

Double-stranded DNA of the complete ITS region (ITS1, 5.8S rRNA gene and ITS2) of the test species was amplified with the universal primers ITS5 (forward primer; 5' GGAAGTAAAAGTCGTAACAAGG $3^{\prime}$ ) and ITS4 (reverse primer; $5^{\prime}$ TCCTCCGCTTATTGATATGC $3^{\prime}$ ) (White et al. 1990). The primers were custom synthesized by Bioserve biotechnologies (Hyderabad, India). Amplification was carried out in $25 \mu \mathrm{L}$ reaction volume with sterile distilled water, $2.5 \mu \mathrm{L} 10 \times$ Taq buffer, $2.0 \mathrm{mM}$ $\mathrm{MgCl}_{2}, 0.6 \mathrm{mM}$ dNTP mixture, $30 \mathrm{pM}$ of each primer, 1.5 U Taq DNA polymerase and approximately $60 \mathrm{ng}$ of genomic DNA. PCR was performed in an Eppendorf Mastercycler Gradient (Hamburg, Germany). The amplification profile was $94{ }^{\circ} \mathrm{C}$ for 4 min followed by 35 cycles of $94{ }^{\circ} \mathrm{C}$ for $80 \mathrm{~s}, 60{ }^{\circ} \mathrm{C}$ for $40 \mathrm{~s}, 72^{\circ} \mathrm{C}$ for $80 \mathrm{~s}$ with a final extension step at $72{ }^{\circ} \mathrm{C}$ for $4 \mathrm{~min}$.

PCR products were resolved on $1.2 \%$ agarose, $0.5 \times$ TBE gels pre-stained with ethidium bromide $(0.5 \mu \mathrm{g} / \mathrm{ml})$. Simultaneously, 100 bp DNA ladder (Fermentas, Ontario, Canada) was loaded to confirm the size of the amplicon. The gel was visualized under UV radiation in a Camag Reprostar (Camag, Muttenz, Switzerland) and image captured (Canon, Tokyo, Japan). Each experiment was repeated at least three times with all available accessions (Table 1) of each plant species to confirm its reproducibility and repeatability.

\section{Direct sequencing of complete ITS region}

PCR amplified complete ITS region of B. aristata, B. asiatica and $B$. lycium were purified from agarose gel using QIAquick gel extraction kit (Qiagen, Maryland, USA) following manufacturer's instruction. Direct sequencing of the amplicon was done using primers ITS5 and ITS4 in an automated ABI 3100 Genetic Analyser (Applied Biosystems, CA, USA) by Bangalore Genei (Bangalore, India).

Sequence analysis and development of species-specific markers for B. aristata, B. asiatica and B. lycium

Sequence boundaries of the ITS1, 5.8S and ITS2 were determined following the submitted sequence data available on GenBank (http://www.ncbi.nlm.nih.gov/). The complete sequence of the ITS region for each species studied was then deposited at GenBank. Multiple alignment was done with complete ITS sequences of $B$. aristata, $B$. asiatica and B. lycium, employing CLUSTALW (http://www.ebi.ac.uk.clustalw/). Homology percentage was calculated using the following formula:

Homology $\%=\frac{\text { Number of homologous bases in the species compared }}{\text { Total Number of bases in the species compared with }}$

DNA primers capable of giving specific amplification with individual species were developed using NCBI primer blast tool (http://www.ncbi.nlm.nih.gov/tools/primer-blast/). The oligonucleotides were custom synthesized by Bioserve biotechnologies (Hyderabad, India). PCR reaction with the species-specific primer set contained $30 \mathrm{ng}$ of genomic 
DNA, $2.5 \mu \mathrm{l}$ of $10 \times$ assay buffer, $1.5 \mathrm{mM} \mathrm{MgCl} 2,0.3 \mathrm{mM}$ dNTP mix, $30 \mathrm{pM}$ of each primer and $1 \mathrm{U}$ of Taq DNA polymerase (Bangalore Genei, India) with the volume made up to $25 \mu \mathrm{l}$ with sterile distilled water. PCR program conditions optimized for the species-specific primer sets were as follows: $94{ }^{\circ} \mathrm{C}$ for $4 \mathrm{~min}$, followed by 35 cycles of $35 \mathrm{~s}$ at $94{ }^{\circ} \mathrm{C}, 30 \mathrm{~s}$ at $60{ }^{\circ} \mathrm{C}$ and $45 \mathrm{~s}$ at $72{ }^{\circ} \mathrm{C}$ with a final extension step for $3 \mathrm{~min}$ at $72{ }^{\circ} \mathrm{C}$.

\section{Results}

Extraction of genomic DNA and amplification of complete ITS sequence

After trying with many reported DNA extraction protocols, the method described in "Materials and methods" section repeatedly yielded good quality, high molecular weight genomic DNA from the dried stem samples of B. aristata, $B$. asiatica and B. lycium. The procedure yielded 400-600 ng of DNA per $100 \mathrm{mg}$ of tissue. An absorbance $\left(A_{260} / A_{280}\right)$ ratio of 1.6-1.8 indicated insignificant levels of contaminating proteins and polysaccharides. The universal primers ITS5 (forward) and ITS4 (reverse) amplified the complete ITS region (ITS1, 5.8S rRNA gene and ITS2) yielding an amplicon of approximately $700 \mathrm{bp}$ for all the three species studied (Fig. 1).

Sequencing of complete ITS region and homology analysis

Direct sequencing of the gel purified amplicon yielded a 652 bp sequence for $B$. aristata (GeneBank accession no. GQ259132) (Fig. 2a), 678 bp for B. asiatica (GeneBank accession no. GQ259133) (Fig. 2b) and 765 bp for B. lycium (GeneBank accession no. GQ259134) (Fig. 2c). BLAST analysis indicated that the sequences were novel. Multiple alignment of rRNA and ITS sequence of Berberis spp. under study revealed inter-species sequence variation (Fig. 3). The homology score in the ITS1, 5.8S rRNA gene and ITS2

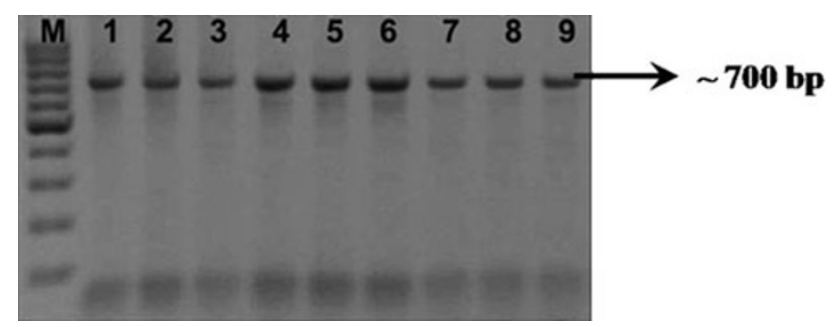

Fig. 1 PCR amplification of complete ITS sequence. Lane $M 100 \mathrm{bp}$ DNA ladder; lanes 1-3 B. aristata; lanes 4-6 B. asiatica; lanes 7-9 B. lycium. Approximately, $700 \mathrm{bp}$ amplicon can be observed with all samples of Berberis spp. regions of $B$. aristata, $B$. asiatica and B. lycium are shown in Table 2. Interestingly, the data from sequence alignment indicated that the ITS1, 5.8S rRNA gene and ITS2 regions of each species were quite unique and different from each other. Maximum homology was observed in the ITS1 regions of B. asiatica and B. lycium $(97.86 \%)$ while lowest $(56.41 \%)$ was seen in the ITS1 regions of $B$. asiatica and B. aristata (Table 2). The sequence variation was used to develop species-specific markers for individual species.

Designing of species-specific markers and validation

NCBI primer blast tool was used to develop and validate the species-specific markers. The details of species-specific primers designed and amplicon size are given in Table 3. The $B$. aristata-specific primers (AR1F and AR1R) yielded $405 \mathrm{bp}$ amplicon with all the accessions of $B$. aristata only and did not produce any amplification with $B$. asiatica and B. lycium (Fig. 4). Similarly, primers AS1F and AS1R produced amplification (401 bp) only with $B$. asiatica accessions (Fig. 5), while BL2F and BL2R primers yielded 232 bp amplicon only with B. lycium samples (Fig. 6).

\section{Discussion}

One of the impediments in the acceptance of herbal formulations is the lack of standardization and quality control profiles. Due to the complex nature and inherent variability of the chemical constituents of plant-based drugs, it is difficult to establish quality control parameters using phytochemical tools (World Health Organization 2000). The pitfalls associated with the common conventional Pharmacognosy methods like macro-microscopic examination and phytochemical analysis have led to the search of definitive methods for authentication of herbs and formulations (Yan-Bo et al. 2007). Chinese pharmacopoeia has already started including modern DNA-based details to distinguish herbs (Yip et al. 2007).

Our experience with B.aristata, B. asiatica and B. lycium indicates that they can hardly be distinguished based on their morphology and histology (data unpublished). Controversial reports on the berberine content of these three species have been reported in the past. A comparative high performance thin layer chromatography (HPTLC) analysis of $B$. asiatica with $B$. aristata showed identical profile with lesser berberine content in the former (Srivastava et al. 2004). While, Andola et al. (2010) have reported that $B$. asiatica has higher berberine content followed by $B$. lycium and B. asiatica. These inconsistent reports indicate the disadvantage of chemical marker and also insist on a robust technique for differentiating these three species. 
Fig. 2 Complete ITS sequence of $B$. aristata, $B$. asiatica and $B$. lycium. Species-specific 20 mer primers (forward and reverse) for each species is shown underlined in the sequence

\section{(a) B. aristata (GenBank accession no. GQ259132)}

1 TTCTGTGTCTGTTTPCTTTCCTTTTTAATCGGCCCCCCCCTCCTGAGTAGCTGTACAG

61 TCGTAGTGACTGCGAGATCATGTGAATGATAGCAGAAGATCGCGACTGTGACACtATATA

121 GAGAGATACGTCTCTGACTCTCCTCGATTCGATCGAGAGTGCTGTCGCATCTCGCTCTGA

AR1F

181 TAAATACAACTCGCGATCAGCGCAAGACAATAGATGAATAGCTGCCTGCTCTGCAAGATG

241 TATGCTATCTGATATCGACGACTCCTCGCAGAGGATATCTCGCTCTCGCATCGAAGAAGA

301 ACGTAGCGAGGAGCGATACTGGTGTGAGATGCAGAGACCCGTGAACCATCGAATTTTTGA

361 ACCATGTGCGCCAGGACCACTAGGCTGAGGCACGTCTGCCTGGGGTCACGCGCGTCGCGC

421 TCGGCACGGGCGGTGTTTTCGTGTTGGTGGGCGGGGGTTGGCCACCGGCTGTCTCGGCTC

481 GGTGGGCCTGGTGGTGGCCTCGGGCGGTGGGCTCGCGGTCTTGGTGGTCTAGGCCCCTT

541 CGTCGTGGACCGGCGTCGTGTTTGCCTGTTGACGTCGGGCTTGCGGGCCGTGTGTTTGCA

AR1R

601 TTTGCGCTCGCCCTGCCCCCGTTGTCCCGTGGGGGCGCTGTGCGCCAGGAAT

(b)B. asiatica (GenBank accession no. GQ259133)

1 TTGAAAAGTAAAGTTCGTACAAGGTTTCCGTAGGTGAACTGCGGAAGGATCATTGTTGAA AS1F

61 ACCGCATAGCAGAAAGACCCGCGAACTTGTGAACAACTATATTGGGAGAGGGATACGGGT

121 CTCTTGGACTCCTTCCCTCGATTTCGGACCGAGGAGTGCCCTTGTTGGCATTCTTTGGCT

181 CTGATAAAATAACAAACTCGCGATCAGCGCCAAGGAAAATTAAATGGAAATAGCTTGCCC

241 TTGCTCTTGCAAGATGGTATTGCTTATCTGATATTCGAACGACTCTCGGCAATGGATATC

301 TCGCGCTCGCATCGATGAAGAACGTAGCGAAATGCGATACTTGGTGTGAATTGCAGAATC

361 CCGTGAACCATCGAGTTTTTGAACGCAAGTTGCGCCCAAACCACTAGGCTGAGGCACGTC

AS1R

421 TGCCTGGGGTCACACGCGTCGCGCTCGACACGGGCGGTGTTTTCGTGTTGGTGGGCGGGG

481 GTTGCCACCGGCTGTCTCGGCTCGGTGGGCCTGGGTGGTGGCCTCGGGCGGTGGGCGTCG

541 CGGTTGTGGTGGTTTGGTCCCCTTTTGTCGTGGACCGGCGTCGTGTTTGCCTCGTTGACG

601 CTCGGGGGGCGGGCCCTGTGTGTTCGTCTGGGGCGCCTTGCGCCCCGGGTCGTGGGGGGC 661 GCGCTGGGCACCAGGAAC

(c) B. lycium (GenBank accession no. GQ259134)

1 ATGCACACTAGGTACtTATCTGTGTGATTGATAGTATATATTAGTACAGGCATGTCAGAT

61 TATATATGGACCACGGCGCTTCATCCAAAAACCTCCCTGGAAAAGTAAATTCGACAAGG

BL2F

121 TTTCCGTAGGTGAACTGCGGAAGGATCATTGTTGAAACCCATAGCAGAAAGACCCGCGAA

181 CTTGTGAACAACTATATTGGGAGAGGGATACGGGTCTCTTGGACTCCTCCCTCGATTTCG

241 GACCGAGGAGTGCCCTTGTTGGCATTCTTTGGCTCTGATAAAATAACAAACTCGCGATCA

301 GCGCCAAGGAAAATTAAGTGGAAGTAGCTTGCCCCTTGCTCTTGCAAGATGGTATTGCTT

\section{BL2R}

361 ATCTGATATTCGAACGACTCTCGGCGGTGGGTATCTCGCGCTCGCATCGGTGGGGGACGT

421 GGCGGGGTGCGGTACTTGGTGTGGGTTGCGGGGTCCCGTGGACCGTCGGGTTTTTGGGCC

481 GGGTTGCGCCCGGAACCGCTTGGCTGGGGCGCGTCTGCCTGGGGTCGCGCGCGTCGCGCT

541 CGGCGCGGGCGGTTTPTCGTGTTGGTGGGCGGGGGTPCCCCGGCTCTCTCGGCTCGGT

601 GGGCCGGGGTGGTGGCCTCGGGCGGGGGGCGTCGCGGTCTCTGTGCCAGGGCCCCCCCTT

661 CCAAGCCACGTCGTTCTCCTGTTGACTCTGTCTTGCGGGCCCGTTCTTTCGTGGGACTCG

721 CCGTGCTCCCCGGGGCGTCGTCCGCCCGCTGTCTCTCAAGCAAAT 
Fig. 3 Multiple alignment of the complete ITS sequence of B. aristata, B. asiatica and B. lycium
B.asiatica B. lycium B.aristata

B.asiatica B. 1 ycium

B. aristata

B.asiatica

B. 1ycium

B.aristata

B.asiatica

B. Iycium

B.aristata

B.asiatica

B. lycium

B.aristata

B.asiatica

B. lycium

B.aristata

B.asiatica

B. 1 ycium

B.aristata

B.asiatica

B. lycium

B.aristata

B.asiatica

B. lycium

B.aristata

B.asiatica

B.1ycium

B. aristata

B.asiatica

B. 1ycium

B.aristata

B.asiatica

B. 1 ycium

B.aristata

B. asiatica

B. 1 ycium

B.aristata

B.asiatica

B. lycium

B. aristata
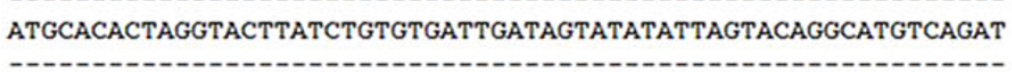

TTGAAAAGTAAAGTTCGTACAAG TATATATGGACCACGGCGCTTCATCCAAAAACCTCCCTGGAAAAGTAAAGTTCG-ACAAG ------ TTCTGTGTCTGTTTTCTTTTCCTTTTTTACTCGGCCCCCCCCT-CCTGA

GTTTCCGTAGGTGAACTGCGGAAGGATCATTGTTGAAACCGCATAGCAGAAAGACCCGCG GTTTCCGTAGGTGAACTGCGGAAGGATCATTGTTGAAACC-CATAGCAGAAAGACCCGCG GTAGCTGTACAGTCGTAGTGACTGCGAGATCATGTGAATG--ATAGCAGAAGA--TCGCG

AACTTGTGAACAACTATATTGGGAGAGGGATACGGGTCTCTTGGACTCCTTCCCTCGATT AACTTGTGAACAACTATATTGGGAGAGGGATACGGGTCTCTTGGACTCCT-CCCTCGATT A--CTGTGAC--ACTATAT----AGAGAGATACG----TCTCTGACTCTC---CTCGATT

TCGGACCGAGGAGTGCCCTTGTTGGCATTCTTTGGCTCTGATAAAATAACAAACTCGCGA TCGGACCGAGGAGTGCCCTTGTTGGCATTCTTTGGCTCTGATAAAATAACAAACTCGCGA C--GATCGAG-AGTGCTGTCGCA------TCTCGCTCTGATAAAT--ACAA-CTCGCGA

TCAGCGCCAAGGAAAATTAAATGGAAATAGCTTGCCC-TTGCTCTTGCAAGATGGTATTG TCAGCGCCAAGGAAAATTAAGTGGAAGTAGCTTGCCCCTTGCTCTTGCAAGATGGTATTG TCAGCGCAAGACAA---TAGATG--AATAGCT-GCC---TGCTCT-GCAAGATG-TATG-

CTTATCTGATATTCGAACGACTCTCGGCAATGGATATCTCGCGCTCGCATCGATGAAGAA CTTATCTGATATTCGAACGACTCTCGGCGGTGGGTATCTCGCGCTCGCATCGGTGGGGGA -CTATCTGATATC--GACGACTCCTCGCAGAGGATATCTCGCTCTCGCATCGAAGAAGAA

CGTAGCGAAATGCGATACTTGGTGTGAATTGCAGAATCCCGTGAACCATCGAGTTTTTGA CGTGGCGGGGTGCGGTACTTGGTGTGGGTTGCGGGGTCCCGTGGACCGTCGGGTTTTTGG CGTAGCGAGGAGCGATACT-GGTGTGAGATGCAGAGACCCGTGAACCATCGAATTTTTGA

ACGCAAGTTGCGCCCA-AACCACTAGGCTGAGGCACGTCTGCCTGGGGTCACACGCGTCG GC-CGGGTTGCGCCCGGAACCGCTTGGCTGGGGCGCGTCTGCCTGGGGTCGCGCGCGTCG AC-CATGT-GCGCCAG-GACCACTAGGCTGAGGCACGTCTGCCTGGGGTCACGCGCGTCG

CGCTCGACACGGGCGGTGTTTTCGTGTTGGTGGGCGGGGGTTG-CCACCGGCTGTCTCGG CGCTCGGCGCGGGCGGTGTTTTCGTGTTGGTGGGCGGGGGTT--CCGCCGGCTCTCTCGG CGCTCGGCACGGGCGGTGTTTTCGTGTTGGTGGGCGGGGGTTGGCCACCGGCTGTCTCGG

CTCGGTGGGCCTGGGTGGTGGCCTCGGGCGGTGGGCGTCGCGGTTGTGGTGGTTTGGTCC CTCGGTGGGCCGGGGTGGTGGCCTCGGGCGGGGGGCGTCGCGGTCTCTGTGCCAGGGCCC CTCGGTGGGCCTGG-TGGTGGCCTCGGGCGGTGGGCGTCGCGGTCTTGGTGGTCTAGGCC

CCTTTTGTCGTGGACCGGCGTCGTGTTTGCCTCGTTGACGCTCGGGGGGCGGGCCCTGTG CCCCTT----CCAAGCCACGTCGTTCT---CCTGTTGACTCT-GTCTTGCGGGCCC-GTT CCTTCG-TCGTGGACCGGCGTCGTGTTTG-CCTGTTGACGTCGGGCTTGCGGGCCGTGTG

TGTTCGTCTG-GGGCGCCTTGCGCCCCGGGTCGTGGGGGGCGCGCTGGGCACCAGGAACCTTTCGTGGG-ACTCGCCGTGCTCCCCGGGGCGTCGTCCGCCCGCTGTCTCTCAAGCAAA TTTGCATTTGCGCTCGCCCTGC-CCCCGTTGTCCCGTGGGGGCGCTGTGCGCCAGGAAT-

$\mathrm{T}$

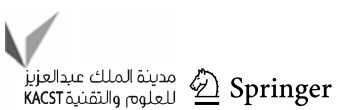


Table 2 The Homology Score in the ITS Region of B. aristata, B. asiatica and B. lycium

\begin{tabular}{|c|c|c|c|c|c|c|c|c|c|}
\hline & \multicolumn{3}{|c|}{ B. aristata } & \multicolumn{3}{|c|}{ B. asiatica } & \multicolumn{3}{|c|}{ B. lycium } \\
\hline & ITS1 & $5.8 \mathrm{~S}$ & ITS2 & ITS1 & $5.8 \mathrm{~S}$ & ITS2 & ITS1 & $5.8 \mathrm{~S}$ & ITS2 \\
\hline \multicolumn{10}{|c|}{ B. aristata } \\
\hline ITS1 & - & - & - & $67.00 \%$ & - & - & $72.08 \%$ & - & - \\
\hline $5.8 \mathrm{~S}$ & - & - & - & - & $82.89 \%$ & - & - & $72.36 \%$ & - \\
\hline ITS2 & - & - & - & - & - & $84.86 \%$ & - & - & $80.27 \%$ \\
\hline \multicolumn{10}{|c|}{ B. asiatica } \\
\hline ITS1 & $56.41 \%$ & - & - & - & - & - & $97.86 \%$ & - & - \\
\hline $5.8 \mathrm{~S}$ & - & $83.56 \%$ & - & - & - & - & - & $78.76 \%$ & - \\
\hline ITS2 & - & - & $86.72 \%$ & - & - & - & - & - & $74.88 \%$ \\
\hline \multicolumn{10}{|c|}{ B. lycium } \\
\hline ITS1 & $60.94 \%$ & - & - & $99.14 \%$ & - & - & - & - & - \\
\hline $5.8 \mathrm{~S}$ & - & $75.34 \%$ & - & - & $79.45 \%$ & - & - & - & - \\
\hline ITS2 & - & - & $78.44 \%$ & - & - & $72.47 \%$ & - & - & - \\
\hline
\end{tabular}

Table 3 Details of the species-specific markers designed using the ITS sequence

\begin{tabular}{llll}
\hline Plant species & Name of the marker & Sequence of the DNA marker $\left(5^{\prime} \rightarrow 3^{\prime}\right)$ & Product $(\mathrm{bp})$ size \\
\hline B. aristata & AR1F & TCTCGCTCTGATAAATACAACTCG & 405 \\
& AR1R & CGTCAACAGGCAAACACGAC \\
B. asiatica & AS1F & GTACAAGGTTTCCGTAGGTGAACT & 401 \\
AS1R & GTGCCTCAGCCTAGTGGTTTG & \\
& BL2F & TTCGACAAGGTTTCCGTAGG & 232 \\
& BL2R & AGAGCAAGGGGCAAGCTACT & \\
\hline
\end{tabular}

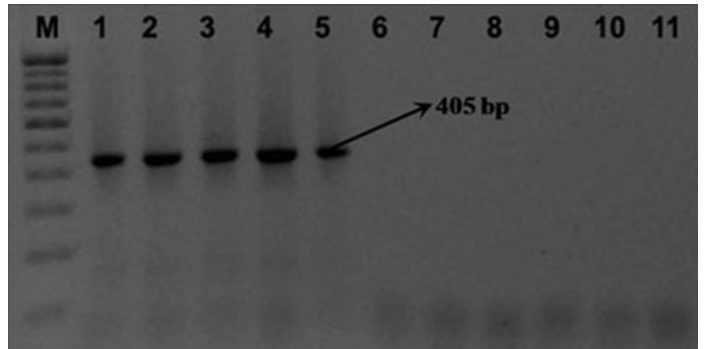

Fig. 4 PCR amplification of genomic DNA from Berberis spp. with $\mathrm{AR} 1 \mathrm{~F}$ and AR1R. Lane $M 100$ bp DNA ladder; lanes 1-5 B. aristata; lanes 6-8 B. asiatica; lanes 9-11 B. lycium. A $405 \mathrm{bp}$ amplicon is observed only in B. aristata samples

The commonly followed DNA fingerprinting techniques like randomly amplified polymorphic DNA (RAPD), restriction fragment length polymorphism (RFLP) and amplified fragment length polymorphism (AFLP) have poor reproducibility of markers (Yan-Bo et al. 2007). Recently, more reproducible sequence characterized amplified region (SCAR) markers have been developed for many medicinal plant species to distinguish from their substitutes or adulterants (Devaiah and Venkatasubramanian 2008; Devaiah

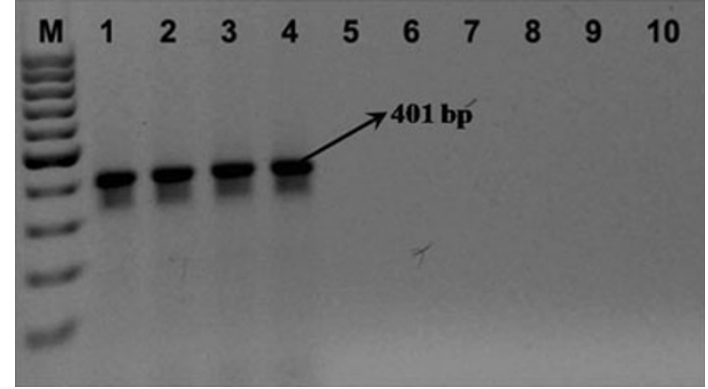

Fig. 5 PCR amplification of genomic DNA from Berberis spp. with AS1F and AS1R. Lane M 100 bp DNA ladder; lanes 1-4 B. asiatica; lanes 5-7 B. lycium; lanes 8-10 B. aristata. A $401 \mathrm{bp}$ amplicon is observed only in $B$. asiatica samples

et al. 2010). Many studies in recent years have employed ITS sequences as genetic markers for various species at generic and intrageneric levels. The length and sequences of ITS regions of ribosomal RNA gene repeats are believed to rapidly turn over thus capturing measurable variations between species (Dubouzet and Shinoda 1999). Universal PCR primers designed from highly conserved regions flanking the ITS region, relatively small in size 


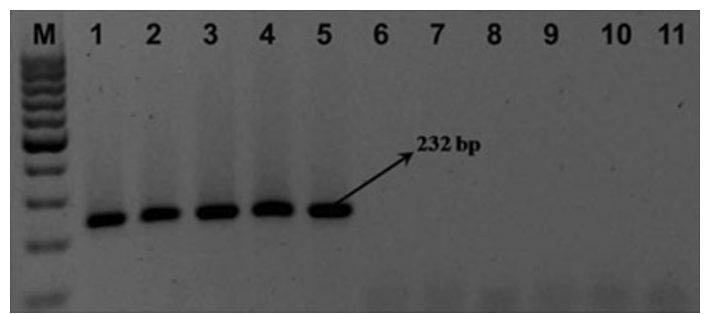

Fig. 6 PCR amplification of genomic DNA from Berberis spp. with BL2F and BL2R. Lane M 100 bp DNA ladder; lanes 1-5 B. lycium; lanes 6-8 B. aristata; lanes 9-11 B. asiatica. A 232 bp amplicon is observed only in $B$. lycium samples

(600-700 bp) and high copy number ( $>100$ per cell), enable easy amplification of the ITS region (Yan-Bo et al. 2007; Yip et al. 2007). These advantages have made ITS region and ribosomal RNA gene sequence as preferred choice for molecular typing. Novak et al. (2007) have reported ITS sequence-based authentication of Echinacea spp. in extracts. Balasubramani et al. (2010) have reported ITS sequence-based DNA markers to differentiate Tribulus spp. of the Zygophyllaceae family. Watthanachaiyingcharoen et al. (2010) have reported 18S rRNA gene-based PCRRFLP to distinguish Coscinium fenestratum from other genus in the Menispermaceae family.

The main problem with DNA-based methods for identification is the presence of phenolic compounds, acidic polysaccharides and pigments that hinder the PCR amplification. This can be avoided by choosing the most suitable DNA extraction process that helps to eliminate the PCR inhibitors. DNA-based methods have been successfully used to even authenticate herbal constituents in commercial herbal preparations in which the components have been ground, boiled, concentrated, dried and blended (Yip et al. 2007). DNA information may not be directly correlated with the amounts of the active ingredients and this is one disadvantage.

In this study, we have described ITS sequence-based efficient and reliable DNA markers to identify and distinguish $B$. aristata, B. asiatica and B. lycium. These markers can be used as a molecular pharmacognostic tool for quality control of herbal raw drugs.

Acknowledgments Financial support for this study was provided as "Centre of Excellence" grant from the Ministry of Environment and Forests, Government of India. Authors wish to thank Dr. K. Ravikumar and Mr. R. Murugan, botanists of FRLHT for authentication of plant samples and useful discussion. Thanks are due to Prof. K.V. Krishnamurthy for his suggestions in preparing this manuscript.

Open Access This article is distributed under the terms of the Creative Commons Attribution Noncommercial License which permits any noncommercial use, distribution, and reproduction in any medium, provided the original author(s) and source are credited.

\section{References}

Affuso F, Ruvolo A, Micillo F, Saccà L, Fazio S (2009) Effects of a nutraceutical combination(berberine, red yeast rice and policosanols) on lipid levels and endothelial functionrandomized, double-blind, placebo-controlled study. Nutr Metab Cardiovasc Dis. doi:10.1016/j.physletb.2003.10.071

Ahmad M, Alamgeer SharifT (2009) A potential adjunct to insulin: Berberis lycium Royle. Diabetol Croat 38:13-18

Andola HC, Rawal RS, Rawat MSM, Bhatt ID, Purohit VK (2010) Analysis of berberine content using HPTLC fingerprinting of root and bark of three Himalayan Berberis species. Asian $\mathbf{J}$ Biotech 2:239-245

Anonymous (1999) The Ayurvedic Pharmacopoeia of India, Part I, Vol II. Government of India, Ministry of Health and Family Welfare, Department of Indian Systems of Medicine \& Homoeopathy, New Delhi, pp 33-34

Anonymous (2003) The Ayurvedic formulary of India (Part II). Government of India, Ministry of Health and Family Welfare, Department of Indian Systems of Medicine \& Homoeopathy, New Delhi, pp 311

Balasubramani SP, Murugan R, Ravikumar K, Venkatasubramanian P (2010) Development ofITS sequence based molecular marker to distinguish, Tribulus terrestris L. (Zygophyllaceae) from its adulterants. Fitoterapia 81:503-508. doi:10.1016/j.fitote.2010. 01.002

Biswas TK, Mukherjee B (2003) Plant medicines of Indian origin for wound healing activity: a review. Int $\mathrm{J}$ Low Extrem Wounds 2:25-39

Chandraa P, Purohita AN (1980) Berberine contents and alkaloid profile of Berberis species from different altitudes. Biochem Syst Ecol 8:379-380

Devaiah KM, Venkatasubramanian P (2008) Genetic characterization and authentication of Embelia ribes using RAPD-PCR and SCAR marker. Planta Med 74:194-196

Devaiah KM, Balasubramani SP, Venkatasubramanian P (2010) Development of RandomlyAmplified Polymorphic DNA based SCAR marker for identification of Ipomoeamauritiana Jacq (Convolvulaceae). eCAM. doi:10.1093/ecam/neq023

Dubey NK, Kumar R, Tripathi P (2004) Global promotion of herbal medicine: India's opportunity. Curr Sci 86:37-41

Dubouzet JG, Shinoda K (1999) Relationships among old and new world Alliums according to ITS DNA sequence analysis. Theor Appl Genet 98:422-433

Fai FC, Ngan FN (2002) Quantification of DNA. In: Shaw PC, Wang J, But H-PP (eds) Authentication of Chinese medicinal materials by DNA technology. World Scientific, Singapore, pp 25-42

Kirtikar KR, Basu BD (1995) Indian medicinal plants. International Book Publications, Dehradun, pp 102-103

Kumar EP, Elshurafa AA, Elango K, Subburaju T, Suresh B (1998) Anti-tumour effect of Berberis asiatica Roxb. ex DC. on Dalton's lymphoma ascites. Anc Sc Life 17:290-299

Milligan BG (1998) DNA isolation. In: Hoelzel AR (ed) Molecular genetic analysis of populations. IRL Press, Oxford, p 263

Novak J, Grausgruber-Gröger S, Lukas B (2007) DNA-based authentication of plant extracts. Food Res Int 40:388-392

Rao RR, Hussain T, Datt B, Garg A (1998) Revision of the Family Berberididaceae of India-I. Rheedea 8:1-66

Rao RR, Hussain T, Datt B, Garg A (1999) Palynology of Berberis (Berberidaceae). Rheedea 9:115-146

Sack RB, Froehlich JL (1982) Berberine inhibits intestinals secretory response of Vibriocholerae and Echerichia coli entorotoxin. Infect Immun 35:471-475

Saied S, Batool S, Naz S (2007) Phytochemical studies of Berberis aristata. J Basic Appl Sci 3:1-4 
Singh J, Kakkar P (2009) Antihyperglycemic and antioxidant effect of Berberis aristata root extract and its role in regulating carbohydrate metabolism in diabetic rats. J Ethnopharmacol 123:22-26

Singh M, Srivastava S, Rawat AK (2007) Antimicrobial activities of Indian Berberis species. Fitoterapia 78:574-576

Sohni YR, Kaimal P, Bhatt RM (1995) The antiamoebic effect of a crude drug formulation of herbal extracts against Entamoeba histolytica in vitro and in vivo. J Ethnopharmacol 45:43-52

Srivastava SK, Rawat AKS, Mehrotra S (2004) Pharmacognostic evaluation of roots of Berberis asiatica. Pharma Biol 42:467-473

Ved DK, Goraya GS (2008) Demand and supply of medicinal plants in India. Bishen Singh Mahendra Pal Singh, Dehradun, pp 112, 134,154

Watthanachaiyingcharoen R, Komatsu K, Zhu S, Vajragupta O, Leelamanit W (2010) Authentication of Coscinium fenestratum among the other menispermaceae plants prescribed in Thai folk medicines. Biol Pharm Bull 33:91-94
White TJ, Bruns T, Lee S, Taylor J (1990) Amplification and direct sequencing of fungal ribosomal RNA genes for phylogenetics. In: Innis MA, Gelfand DH, Sninsky JJ, Thomas J (eds) PCR protocols: a guide to methods and applications. Academic Press, San Diego, p 315

Wongbutdee J (2009) Physiological effects of Berberine. Thai Pharm Health Sci J 4:78-83

World Health Organization (2000) WHO general guidelines for methodologies on research and evaluation of traditional medicine. Available at: http://whqlibdoc.who.int/hq/2000/WHO_EDM_ TRM_2000.1.pdf (Accessed 22 February 2010)

Yan-Bo Z, Pang-Chui S, Cho-Wing S, Zheng-Tao W, Yao T (2007) Molecular authentication of Chinese herbal materials. J Food Drug Anal 15:1-9

Yip PY, Chau CF, Mak CY, Kwan HS (2007) DNA methods for identification of Chinese medicinal materials. Chin Med 2:9 